\title{
COVID-19 and associations with frailty and multimorbidity: a prospective analysis of UK Biobank participants
}

\author{
S. J. Woolford ${ }^{1}$. S. D'Angelo ${ }^{1}$ - E. M. Curtis ${ }^{1}$ - C. M. Parsons ${ }^{1} \cdot$ K. A. Ward ${ }^{1}$ - E. M. Dennison ${ }^{1} \cdot$ H. P. Patel $^{1,2,3,4}$. \\ C. Cooper ${ }^{1,4,5}$. N. C. Harvey ${ }^{1,4}(\mathbb{D}$
}

Received: 8 June 2020 / Accepted: 7 July 2020 / Published online: 23 July 2020

(c) The Author(s) 2020

\begin{abstract}
Background Frailty and multimorbidity have been suggested as risk factors for severe COVID-19 disease.

Aims We investigated, in the UK Biobank, whether frailty and multimorbidity were associated with risk of hospitalisation with COVID-19.

Methods 502,640 participants aged 40-69 years at baseline (54-79 years at COVID-19 testing) were recruited across UK during 2006-10. A modified assessment of frailty using Fried's classification was generated from baseline data. COVID-19 test results (England) were available for 16/03/2020-01/06/2020, mostly taken in hospital settings. Logistic regression was used to discern associations between frailty, multimorbidity and COVID-19 diagnoses, after adjusting for sex, age, BMI, ethnicity, education, smoking and number of comorbidity groupings, comparing COVID-19 positive, COVID-19 negative and non-tested groups.

Results 4510 participants were tested for COVID-19 (positive $=1326$, negative $=3184$ ). 497,996 participants were not tested. Compared to the non-tested group, after adjustment, COVID-19 positive participants were more likely to be frail (OR $=1.4$ $[95 \% \mathrm{CI}=1.1,1.8])$, report slow walking speed $(\mathrm{OR}=1.3[1.1,1.6])$, report two or more falls in the past year $(\mathrm{OR}=1.3[1.0$, $1.5]$ ) and be multimorbid ( $\geq 4$ comorbidity groupings vs $0-1:$ OR $=1.9[1.5,2.3]$ ). However, similar strength of associations were apparent when comparing COVID-19 negative and non-tested groups. However, frailty and multimorbidity were not associated with COVID-19 diagnoses, when comparing COVID-19 positive and COVID-19 negative participants.

Discussion and conclusions Frailty and multimorbidity do not appear to aid risk stratification, in terms of positive versus negative results of COVID-19 testing. Investigation of the prognostic value of these markers for adverse clinical sequelae following COVID-19 disease is urgently needed.
\end{abstract}

Keywords COVID-19 · Frailty $\cdot$ Musculoskeletal $\cdot$ UK biobank · Osteoporosis · Epidemiology

\section{Background}

S. J. Woolford and S. D'Angelo are joint first authors. C. Cooper and N. C. Harvey are joint senior authors.

Electronic supplementary material The online version of this article (https://doi.org/10.1007/s40520-020-01653-6) contains supplementary material, which is available to authorized users.

\section{N. C. Harvey}

nch@mrc.soton.ac.uk

1 MRC Lifecourse Epidemiology Unit, University of Southampton, Southampton, UK

2 Medicine for Older People, University Hospital Southampton, Southampton, UK

3 Academic Geriatric Medicine, University of Southampton, Southampton, UK
The first case of 2019 Novel Coronavirus (COVID-19) disease (caused by the Severe Acute Respiratory Syndrome Coronavirus 2 [SARS-CoV-2]) was reported in Wuhan, China in December 2019 [1]. Since then, the number of

4 NIHR Southampton Biomedical Research Centre, University of Southampton and University Hospital Southampton NHS Foundation Trust, Southampton, UK

5 NIHR Biomedical Research Centre, University of Oxford, Oxford, UK 
global cases have increased rapidly, with the WHO declaring COVID-19 a pandemic in March 2020 [2]. At the time of manuscript preparation, more than 5 million cases have been confirmed across 213 countries and territories, with more than 300,000 associated deaths [3].

The identification of risk factors for contracting COVID19 is crucial, to inform public health policy and to facilitate the appropriate distribution of healthcare resources. Preliminary data from Asia, Europe and the United States suggest that the majority of individuals with COVID-19 are aged $>50$ years, with most deaths occurring in those aged $>60$ years [4-8]. Multimorbidity has also been associated with COVID-19 disease, the need for ventilatory support and higher rates of mortality [4-6, 8]. As a result, COVID-19 patients have frequently been described within the academic discourse as "frail", with this term being used in its more colloquial sense [9-11]. Furthermore, clinical management guidelines, such as those produced by the UK National Institute for Health and Care Excellence (NICE), typically recommend the assessment of frailty as the initial step when triaging suspected COVID-19 patients [12], and frailty is also addressed more widely in recent European guidelines [13]. However, the clinical syndrome of frailty has yet to be formally examined in relation to COVID-19 disease, beyond single case reports [14].

Therefore, we aimed to examine the associations between COVID-19 diagnoses, frailty and multimorbidity within the UK Biobank, a large prospective community cohort of over half a million UK residents.

\section{Methods}

\section{Study population}

This study was a prospective community-based cohort analysis of UK Biobank participants. Between 2006 and 2010 potential participants were invited for recruitment, with inclusion criteria being registered with a general practitioner, living within reasonable travelling distance of an assessment center and being aged 40-69 years. 502,640 participants were recruited across 22 assessment centers in England, Scotland and Wales, with a response rate of 5\%.

\section{Baseline characteristics}

Information on lifestyle, social history and medical history was collected using a series of computer-based touchscreen questionnaires, followed by face-to-face interviews with trained research staff. Recorded data included sex, age, ethnicity, level of educational attainment, alcohol consumption (never or special occasions only; one to three times per month; one to four times per week; or daily or almost daily), smoking status (never smoked; ex-smoker; or current smoker) and number of falls in the past year (no falls; only one fall; or more than one fall). Height and weight were also measured by trained research staff using a standardized technique, and BMI was subsequently calculated $\left(\mathrm{kg} / \mathrm{m}^{2}\right)$.

\section{Assessment of frailty}

We calculated frailty using a modified version of five frailty phenotype indicators originally reported by Fried and colleagues [15], and later adapted for use in the UK Biobank dataset [16]. Table 1 outlines the criteria for the frailty indicators used, compared to Fried and colleagues' original definition. The criteria for the low physical activity frailty indicator was further adapted for use in this study, based on a comparable exercise metric within the dataset available to us. Grip strength was measured using a Jamar J00105 hydraulic hand dynamometer, with both right and left hands being assessed, and the higher result used in the analysis. The other frailty indicators were assessed via self-reported touchscreen questionnaire answers. The associations with multiple falls in the past year with COVID-19 diagnoses was also examined, due to the associations of frequent falls with frailty and the frequency of which a fall is the first presentation of the frailty syndrome to healthcare providers $[17,18]$.

As per Fried and colleagues, participants were classified as not frail (0 frailty indicators), pre-frail (1-2 frailty indicators) or frail ( $\geq 3$ more frailty indicators). Frailty status was not calculated for participants with missing data for three or more frailty indicators, as per Fried and colleagues' methodology.

\section{Assessment of multimorbidity}

Participants reported doctor-diagnosed chronic health conditions during face-to-face interviews at study recruitment, apart from cancer, which was reported during touchscreen questionnaires. To avoid repeated counting of closely related or clinically similar chronic health conditions, comorbidities were categorised according to 43 comorbidity groupings, originally established for a large epidemiological study in Scotland [19], and subsequently amended for use in the UK Biobank [20]. Supplementary Table 1 shows the full list of comorbidity groupings and the corresponding health conditions. Number of comorbidity groupings were then summed, and categorised ( $0-1 ; 2 ; 3$ or $\geq 4$ comorbidity groupings).

\section{COVID-19 testing}

COVID-19 diagnoses were sourced via available COVID19 test results within the UK Biobank dataset at the time of manuscript preparation (from 16th March 2020 to 1st June 2020), sourced from Public Health England [21]. The vast 
Table 1 Frailty indicators originally adapted for use in the UK Biobank by Hanlon and colleagues, based on Fried and colleagues original frailty phenotype

\begin{tabular}{|c|c|c|}
\hline & $\begin{array}{l}\text { Cardiovascular Health Study frailty indicators (Fried and } \\
\text { colleagues) [15] }\end{array}$ & $\begin{array}{l}\text { Adapted UK Biobank frailty indicators (Hanlon and col- } \\
\text { leagues) [16] }\end{array}$ \\
\hline \multirow[t]{2}{*}{ Weight loss } & $\begin{array}{l}\text { Self-reported: "In the last year, have you lost more than } \\
10 \text { lb unintentionally?" }\end{array}$ & $\begin{array}{l}\text { Self-reported: "Compared with one year ago, has your } \\
\text { weight changed?" }\end{array}$ \\
\hline & Yes $=1$, no $=0$ & Yes, lost weight $=1$, other $=0$ \\
\hline \multirow[t]{2}{*}{ Exhaustion } & $\begin{array}{l}\text { Self-reported: "How often in the last week (a) did you feel } \\
\text { that everything was an effort, or (b) could you not get } \\
\text { going?" }\end{array}$ & $\begin{array}{l}\text { Self-reported: "Over the past two weeks, how often have } \\
\text { you felt tired or had little energy?" }\end{array}$ \\
\hline & $\begin{array}{l}\text { Moderate amount of the time [3-4 days] or most of the } \\
\text { time }=1, \text { other }=0\end{array}$ & More than half the days or nearly every day $=1$, other $=0$ \\
\hline \multirow[t]{2}{*}{ Low physical activity } & $\begin{array}{l}\text { Self-reported: Minnesota Leisure Time Activity Ques- } \\
\text { tionnaire and Kcal of activity per week subsequently } \\
\text { estimated }\end{array}$ & $\begin{array}{l}\text { Self-reported: "In a typical week, on how many days did you } \\
\text { do } 10 \text { min or more of moderate physical activities like car- } \\
\text { rying light loads, cycling at normal pace? (do not include } \\
\text { walking)"* }\end{array}$ \\
\hline & Lowest $20 \%$ of cohort $=1$, other $=0$ & $0-1$ day/week $=1$, other $=0$ \\
\hline \multirow[t]{2}{*}{ Slow walking speed } & Measured time to walk 15 feet & $\begin{array}{l}\text { Self-reported: "How would you describe your usual walking } \\
\text { pace?" }\end{array}$ \\
\hline & Lowest $20 \%$ of cohort $=1$, other $=0$ & Slow $=1$, other $=0$ Slow $=1$, other $=0$ \\
\hline \multirow[t]{2}{*}{ Grip strength } & $\begin{array}{l}\text { Measured grip strength, adjusted for sex and body-mass } \\
\text { index }\end{array}$ & Measured grip strength \\
\hline & Lowest $20 \%$ of cohort $=1$, other $=0$ & $\begin{array}{l}\text { Sex and body-mass index adjusted cut-offs taken from Fried } \\
\text { and colleagues }\end{array}$ \\
\hline
\end{tabular}

*Criteria not from Hanlon and colleagues, and based on comparable data available for use for the purposes of this study

majority of these COVID-19 tests were via a combined nasal and throat swab. In intensive care settings, lower respiratory secretion samples were also subject to COVID-19 testing. Samples were transported in a medium suitable for viruses (typically a balanced salt solution), and PCR-based testing was performed.

The time period from which COVID-19 testing data were available for analysis from the UK Biobank was during the peak of the UK COVID-19 outbreak, when the overwhelming majority of COVID-19 testing took place in hospital settings. Therefore, it can be assumed that all those who were tested for COVID-19 presented with symptoms, due to COVID-19 or otherwise, severe enough to warrant hospital admission. The background population group represent those not tested for COVID-19, including those who had did not have COVID-19, as well as undiagnosed COVID-19 cases who were asymptomatic or only had mild symptoms. Current prevalence estimates of undiagnosed COVID-19 cases within the UK community population are approximately $0.3 \%$ [22].

\section{Statistical analysis}

Participants were divided into three groups for comparison: (1) participants who tested positive for COVID19 (COVID-19 + ve group), (2) participants who tested negative for COVID-19 (COVID-19 -ve group), and (3) participants who had not been tested for COVID-19 (background population group).

Baseline characteristics of these three groups were analyzed by reporting mean (standard deviation, SD) or median (interquartile range, IQR) as appropriate for continuous variables, and number (percentages) for categorical variables. Differences between groups were tested with unpaired t-tests, Mann-Whitney $U$ tests or Pearson Chisquare tests, as appropriate.

Logistic regression was used to explore the associations between COVID-19+ve vs COVID-19 -ve groups and frailty status, frailty indicators, number of falls in the past year and number of comorbidity groupings, with groups being stratified for age ( $<60$ or $\geq 60$ years at baseline). Covariates considered included sex, age, BMI, ethnicity, educational attainment, smoking status and number of comorbidity groupings (where comorbidity was not the exposure). Similar analyses for COVID-19+ve and COVID-19 -ve groups vs the background population group were also performed.

All analyses were performed with Stata v 15.1 (StataCorp, College Station, Texas, USA). All UK Biobank participants gave written informed consent for data collection, analysis, and linkage at study recruitment. This study had ethics approval as part of overall UK Biobank ethics approval (NHS National Research Ethics Service 
16/NW/0274). We undertook the study under UK Biobank Access Application 3593.

\section{Results}

\section{Study population}

A total of 4510 UK Biobank participants were tested for COVID-19. Of these, 1326 tested positive and 3184 tested negative. 497,996 participants were not tested. 1769 participants had missing data for three or more frailty indicators, and were excluded from any analyses requiring these data.

\section{Baseline characteristics}

Table 2 shows the baseline characteristics of the three comparative groups. The median age ranged from 58 to 60 years by group, consistent with the recruitment criteria of ages 40-69 years. Median age at the time of COVID-19 testing was 70 and 71 years, for those who tested positive and negative respectively. The COVID-19+ve group were more likely to be male, of greater BMI, of Black, Asian or minority ethnic (BAME) ethnicity and lower educational attainment, and less likely to consume alcohol and to have never smoked, when compared with the background population group. They were also more likely to be frail, exhibit a

Table 2 Characteristics of background population, COVID-19+ve and COVID-19 -ve groups

\begin{tabular}{|c|c|c|c|c|c|c|}
\hline & $\begin{array}{l}\text { Background population } \\
n=497,996\end{array}$ & $\begin{array}{l}\text { COVID- } 19+\mathrm{ve} \\
n=1326\end{array}$ & $\begin{array}{l}\text { COVID-19 -ve } \\
n=3184\end{array}$ & $\begin{array}{l}\text { COVID- } \\
19+\text { ve } \\
\text { vs back- } \\
\text { ground } \\
\text { population }\end{array}$ & $\begin{array}{l}\text { COVID-19 } \\
\text {-ve } \\
\text { vs back- } \\
\text { ground } \\
\text { population }\end{array}$ & $\begin{array}{l}\text { COVID-19+ ve } \\
\text { vs COVID-19-ve }\end{array}$ \\
\hline Sex (male) & $226,921(45.6 \%)$ & $696(52.5 \%)$ & $1505(47.3 \%)$ & $<0.001$ & 0.06 & 0.001 \\
\hline Age at baseline (years) & $58.0(50.0,63.0)$ & $58.0(47.0,65.0)$ & $60.0(50.0,65.0)$ & 0.24 & $<0.001$ & 0.02 \\
\hline BMI $\left(\mathrm{kg} / \mathrm{m}^{2}\right)$ & $27.4(4.8)$ & $28.9(5.5)$ & $28.2(5.5)$ & $<0.001$ & $<0.001$ & $<0.001$ \\
\hline Ethnicity (White) & $468,629(94.3 \%)$ & $1141(86.2 \%)$ & $2927(92.1 \%)$ & $<0.001$ & $<0.001$ & $<0.001$ \\
\hline \multicolumn{7}{|l|}{ Educational attainment } \\
\hline College or university degree & $159,914(32.8 \%)$ & $320(24.9 \%)$ & $930(30.1 \%)$ & $<0.001$ & $<0.001$ & 0.001 \\
\hline A level equivalent & $161,195(33.0 \%)$ & $463(36.0 \%)$ & $989(32.0 \%)$ & & & \\
\hline GCSE equivalent or less & $166,883(34.2 \%)$ & $504(39.2 \%)$ & $1176(38.0 \%)$ & & & \\
\hline \multicolumn{7}{|l|}{ Alcohol consumption } \\
\hline At least 3 times per week & $216,969(43.6 \%)$ & $445(33.6 \%)$ & $1295(40.7 \%)$ & $<0.001$ & 0.001 & $<0.001$ \\
\hline \multicolumn{7}{|l|}{ Smoking status } \\
\hline Never smoked & $271,353(54.8 \%)$ & $643(49.0 \%)$ & $1526(48.3 \%)$ & $<0.001$ & $<0.001$ & 0.03 \\
\hline Ex-smoker & $171,339(34.6 \%)$ & $525(40.0 \%)$ & $1194(37.8 \%)$ & & & \\
\hline Current smoker & $52,392(10.6 \%)$ & $145(11.0 \%)$ & $441(14.0 \%)$ & & & \\
\hline \multicolumn{7}{|l|}{ Frailty indicators } \\
\hline Weight loss & $75,053(15.4 \%)$ & $235(18.2 \%)$ & $545(17.5 \%)$ & 0.005 & 0.001 & 0.61 \\
\hline Exhaustion & $61,417(12.8 \%)$ & $231(18.3 \%)$ & $537(17.5 \%)$ & $<0.001$ & $<0.001$ & 0.55 \\
\hline Low physical activity & $98,518(20.9 \%)$ & $261(21.6 \%)$ & $660(22.3 \%)$ & 0.56 & 0.07 & 0.64 \\
\hline Slow walking speed & $40,229(8.2 \%)$ & $203(15.6 \%)$ & $478(15.3 \%)$ & $<0.001$ & $<0.001$ & 0.78 \\
\hline Weakness of grip & $70,738(14.3 \%)$ & $250(19.0 \%)$ & $666(21.1 \%)$ & $<0.001$ & $<0.001$ & 0.13 \\
\hline \multicolumn{7}{|l|}{ Frailty status } \\
\hline Not frail & $251,797(50.7 \%)$ & $566(43.0 \%)$ & $1368(43.2 \%)$ & $<0.001$ & $<0.001$ & 0.99 \\
\hline Pre-frail & $224,559(45.3 \%)$ & $647(49.1 \%)$ & $1553(49.0 \%)$ & & & \\
\hline Frail & $19,895(4.0 \%)$ & $104(7.9 \%)$ & $248(7.8 \%)$ & & & \\
\hline \multicolumn{7}{|l|}{ Falls in past year } \\
\hline$\geq 2$ & $32,704(6.6 \%)$ & $132(10.1 \%)$ & $302(9.5 \%)$ & $<0.001$ & $<0.001$ & 0.58 \\
\hline \multicolumn{7}{|c|}{ Number of comorbidity groupings } \\
\hline $0-1$ & $339,159(68.1 \%)$ & $754(56.9 \%)$ & $1780(55.9 \%)$ & $<0.001$ & $<0.001$ & 0.25 \\
\hline 2 & $92,691(18.6 \%)$ & $281(21.2 \%)$ & $684(21.5 \%)$ & & & \\
\hline 3 & $41,401(8.3 \%)$ & $168(12.7 \%)$ & $367(11.5 \%)$ & & & \\
\hline$\geq 4$ & $24,745(5.0 \%)$ & $123(9.3 \%)$ & $353(11.1 \%)$ & & & \\
\hline
\end{tabular}

Data are mean (SD), median (IQR), number (\%) and $p$ value. Bold text denotes $p$ values $<0.05$ 
number of frailty indicators (weight loss, exhaustion, slow walking speed and weakness of grip), to report two or more falls in the past year and to report a higher number of comorbidity groupings, when compared with the background population group. However, comparison of COVID-19 -ve group with the background population group yielded a similar pattern of results, apart from being less likely to be male.

When comparing COVID-19+ve and -ve groups, COVID-19+ ve participants were more likely to be male, of greater BMI, of BAME ethnicity, greater BMI, of lower educational attainment and consume less alcohol than COVID19 -ve participants. However, the two groups did not differ in terms of frailty status, frailty indicators, falls in the past year or number of comorbidity groupings.

\section{Associations between frailty, falls, multimorbidity and COVID-19 diagnoses}

Table 3 documents the associations between potential COVID-19 risk factors in the COVID-19+ ve group vs the COVID-19 -ve group, also stratified by age $(<60$ or $\geq 60$ years at baseline, corresponding to $<70-74$ and $\geq 70-74$ years at COVID-19 testing). After adjustment for sex, age, BMI, ethnicity, educational attainment, smoking status and number of comorbidity groupings there were no associations between frailty, indicators of frailty, falls in the past year or number of comorbidity groupings and testing positive for COVID-19. Age stratification revealed no additional associations at older or younger ages. However, odds ratios for frailty indicators and multimorbidity were, in general, more likely to be greater than unity in the older age group, compared with those for the younger age group.

Logistic regression models for potential COVID-19 risk factors in COVID-19+ ve or -ve groups vs the background population group are presented in Table 4. After adjustment, both the COVID-19+ ve and -ve groups displayed greater odds of frailty, a number of frailty indicators and higher number of comorbidities, when compared with the background population group. The strength of associations were comparable in both groups.

\section{Discussion}

To our knowledge at the time of manuscript preparation, this is the first study to investigate associations between the frailty syndrome and COVID-19 diagnoses. Importantly, we have demonstrated that such classification may not aid risk

Table 3 Associations for COVID-19 risk factors in COVID-19+ ve vs COVID-19 -ve groups

\begin{tabular}{|c|c|c|c|c|c|c|}
\hline & \multicolumn{3}{|l|}{ Unadjusted } & \multicolumn{3}{|l|}{ Adjusted $^{1}$} \\
\hline & All & $\begin{array}{l}<60 \text { years at base- } \\
\text { line }\end{array}$ & $\begin{array}{l}\geq 60 \text { years at base- } \\
\text { line }\end{array}$ & All & $\begin{array}{l}<60 \text { years at base- } \\
\text { line }\end{array}$ & $\geq 60$ years at baseline \\
\hline \multicolumn{7}{|l|}{ Frailty status } \\
\hline Not frail & Reference & Reference & Reference & Reference & Reference & Reference \\
\hline Pre-frail & $1.0(0.9,1.2)$ & $1.0(0.8,1.1)$ & $1.1(0.9,1.3)$ & $0.9(0.8,1.1)$ & $0.9(0.7,1.0)$ & $1.1(0.9,1.3)$ \\
\hline Frail & $1.0(0.8,1.3)$ & $0.9(0.6,1.3)$ & $1.2(0.8,1.6)$ & $0.9(0.7,1.2)$ & $0.8(0.5,1.2)$ & $1.0(0.7,1.5)$ \\
\hline \multicolumn{7}{|l|}{ Frailty indicators } \\
\hline Weight loss & $1.1(0.9,1.3)$ & $1.0(0.8,1.3)$ & $1.1(0.9,1.4)$ & $1.1(0.9,1.3)$ & $1.0(0.8,1.3)$ & $1.1(0.8,1.4)$ \\
\hline Exhaustion & $1.0(0.8,1.2)$ & $1.0(0.8,1.3)$ & $1.1(0.8,1.4)$ & $1.0(0.8,1.2)$ & $1.0(0.8,1.3)$ & $1.0(0.7,1.3)$ \\
\hline $\begin{array}{l}\text { Low physical activ- } \\
\text { ity }\end{array}$ & $1.0(0.8,1.2)$ & $0.8(0.6,1.0)$ & $1.2(0.9,1.5)$ & $0.9(0.8,1.1)$ & $0.8(0.6,1.0)$ & $1.2(0.9,1.5)$ \\
\hline Slow walking speed & $1.1(0.9,1.4)$ & $0.8(0.6,1.1)$ & $1.2(1.0,1.6)$ & $1.0(0.8,1.2)$ & $0.7(0.5,1.0)$ & $1.2(0.9,1.5)$ \\
\hline Weakness of grip & $0.9(0.8,1.0)$ & $1.0(0.7,1.2)$ & $0.9(0.7,1.1)$ & $0.8(0.7,1.0)$ & $0.9(0.7,1.2)$ & $0.8(0.7,1.0)$ \\
\hline \multicolumn{7}{|l|}{ Falls in past year } \\
\hline $0-1$ & Reference & Reference & Reference & Reference & Reference & Reference \\
\hline$\geq 2$ & $1.1(0.9,1.4)$ & $0.9(0.8,1.1)$ & $1.0(0.9,1.1)$ & $1.1(0.9,1.5)$ & $0.9(0.8,1.1)$ & $1.0(0.9,1.2)$ \\
\hline \multicolumn{7}{|c|}{ Number of comorbidity groupings } \\
\hline $0-1$ & Reference & Reference & Reference & Reference & Reference & Reference \\
\hline 2 & $1.0(0.9,1.2)$ & $1.0(0.8,1.2)$ & $1.1(0.8,1.3)$ & $1.0(0.8,1.2)$ & $1.0(0.7,1.2)$ & $1.0(0.8,1.3)$ \\
\hline 3 & $1.3(1.0,1.6)$ & $0.9(0.7,1.3)$ & $1.3(0.9,1.7)$ & $1.2(0.9,1.5)$ & $0.8(0.6,1.1)$ & $1.2(0.9,1.6)$ \\
\hline$\geq 4$ & $0.9(0.7,1.1)$ & $0.8(0.6,1.2)$ & $0.9(0.7,1.2)$ & $0.8(0.6,1.0)$ & $0.7(0.5,1.1)$ & $0.8(0.6,1.1)$ \\
\hline
\end{tabular}

Data are odds ratio $(95 \% \mathrm{CI})$

${ }^{1}$ Adjusted for sex, age, BMI, ethnicity, educational attainment, smoking status and number of comorbidity groupings (except when analyzing this association) 
Table 4 Associations for COVID-19 risk factors in COVID-19+ ve and COVID19 -ve groups vs background population group

\begin{tabular}{|c|c|c|c|c|}
\hline & \multicolumn{2}{|l|}{ Unadjusted } & \multicolumn{2}{|l|}{ Adjusted $^{1}$} \\
\hline & $\begin{array}{l}\text { COVID-19+ve } \\
\text { vs background } \\
\text { population }\end{array}$ & $\begin{array}{l}\text { COVID-19 -ve } \\
\text { vs background } \\
\text { population }\end{array}$ & $\begin{array}{l}\text { COVID-19+ve } \\
\text { vs background } \\
\text { population }\end{array}$ & $\begin{array}{l}\text { COVID-19 } \\
\text {-ve } \\
\text { vs back- } \\
\text { ground } \\
\text { population }\end{array}$ \\
\hline \multicolumn{5}{|l|}{ Frailty status } \\
\hline Not frail & Reference & Reference & Reference & Reference \\
\hline Pre-frail & $1.3(1.1,1.4)$ & $1.3(1.2,1.4)$ & $1.1(0.9,1.2)$ & $1.1(1.0,1.2)$ \\
\hline Frail & $2.3(1.9,2.9)$ & $2.3(2.0,2.6)$ & $1.4(1.1,1.8)$ & $1.6(1.4,1.8)$ \\
\hline \multicolumn{5}{|l|}{ Frailty indicators } \\
\hline Weight loss & $1.2(1.1,1.4)$ & $1.2(1.1,1.3)$ & $1.1(1.0,1.3)$ & $1.1(1.0,1.2)$ \\
\hline Exhaustion & $1.5(1.3,1.8)$ & $1.5(1.3,1.6)$ & $1.2(1.0,1.4)$ & $1.2(1.1,1.3)$ \\
\hline Low physical activity & $1.0(0.9,1.2)$ & $1.1(1.0,1.2)$ & $0.9(0.8,1.1)$ & $1.0(0.9,1.1)$ \\
\hline Slow walking speed & $2.1(1.8,2.4)$ & $2.0(1.8,2.2)$ & $1.3(1.1,1.6)$ & $1.5(1.3,1.6)$ \\
\hline Weakness of grip & $1.4(1.2,1.6)$ & $1.6(1.5,1.7)$ & $1.1(0.9,1.3)$ & $1.3(1.2,1.5)$ \\
\hline \multicolumn{5}{|l|}{ Falls in past year } \\
\hline $0-1$ & Reference & Reference & Reference & Reference \\
\hline$\geq 2$ & $1.2(1.1,1.3)$ & $1.5(1.3,1.7)$ & $1.3(1.0,1.5)$ & $1.2(1.0,1.3)$ \\
\hline \multicolumn{5}{|c|}{ Number of comorbidity groupings } \\
\hline $0-1$ & Reference & Reference & Reference & Reference \\
\hline 2 & $1.4(1.2,1.6)$ & $1.4(1.3,1.5)$ & $1.3(1.1,1.5)$ & $1.3(1.2,1.4)$ \\
\hline 3 & $1.8(1.5,2.2)$ & $1.7(1.5,1.9)$ & $1.6(1.3,1.9)$ & $1.6(1.4,1.7)$ \\
\hline$\geq 4$ & $2.2(1.8,2.7)$ & $2.7(2.4,3.0)$ & $1.9(1.5,2.3)$ & $2.4(2.1,2.7)$ \\
\hline
\end{tabular}

Data are odds ratio $(95 \% \mathrm{CI})$. Bold text denotes $95 \% \mathrm{CI}$ which do not include 1

${ }^{1}$ Adjusted for sex, age, BMI, ethnicity, educational attainment, smoking status and number of comorbidity groupings (except when analyzing this association) stratification in terms of COVID-19 vulnerability, contrasting with other attributes, such as male sex, BAME ethnicity and greater BMI. Our findings also highlight that many characteristics of those hospitalized with COVID-19 disease are shared by those hospitalized for other reasons. However, it remains possible that factors such as frailty and multimorbidity may influence adverse outcomes following infection with SARS-CoV-2.

There are several limitations to this study. Firstly, the characteristics of participants used to calculate frailty and multimorbidity status for this study were recorded at recruitment into the UK Biobank, between 2006 and 2010. As such, participants may have accumulated markers of frailty or additional comorbidities after initial data collection, and so may be misclassified in the present analysis. The population studied was also relatively young, relative to the wider frail population, when age was recorded at baseline [23]. However, given that such attributes develop over time, participants were substantially older (50-84 years) at time of COVID-19 testing, and we additionally analyzed by age strata. Secondly, the COVID-19 test results used in this study, which are only from England, are also subject to limitations. Given that the majority of tests were undertaken in hospital, we cannot comment on the associations for asymptomatic or low severity COVID-19 cases within the community. Furthermore, the sensitivity of PCR-based testing has been reported as lower than chest CT imaging, potentially due to low viral load at the time of testing or inappropriate testing technique [24, 25]. Therefore, the number of COVID-19 positive diagnoses within our sample may be underrepresented. Thirdly, at the time of manuscript preparation, mortality data for those tested for COVID-19 are not yet available within the UK Biobank resource. As such, we cannot comment on the associations for frailty and multimorbidity with COVID-19-associated mortality. Fourthly, records of clinical events occurring during hospital admissions are not available within the UK Biobank dataset. Because of this, we also cannot comment on associations with adverse COVID-19 outcomes, such as non-invasive ventilation, intensive care admission or length of hospital stay. Finally, owing to the observational nature of this study causality cannot be inferred from our results.

Frailty is common, with global prevalence in those aged $>85$ years estimated to be $26 \%$ [23]. Frailty is characterised by a physiological vulnerability to stressor events, such as acute illnesses or hospital admissions, after which the individual fails to return to their previous baseline of health [26]. Ultimately, an individual living with frailty 
is predisposed to a significantly increased risk of hospital admission and higher rates of mortality [27]. Multimorbidity, defined as the presence of two or more chronic health conditions, is also common, with UK population estimates ranging from 15 to $30 \%$ [28]. Whilst multimorbidity is often present in those who are frail [29], it is also associated with greater risk of unplanned hospital admissions and increased mortality, independent of frailty [30,31]. Our results are in keeping with this existing literature regarding frailty and multimorbidity, with these populations being more susceptible to physiological insults such as COVID-19, and more likely to experience a severity of disease which requires hospitalisation. Importantly, our results suggest that people living with frailty and multimorbidity are no more likely to require a hospital admission due to COVID-19 compared to other conditions resulting in similar disease severity. Therefore, the reported high rates of COVID-19 diagnoses and mortality in those with multiple health conditions and those who are characterised as frail [4-6, 8] are likely due to the highly contagious nature of COVID-19, and potential susceptibility to severe sequelae, rather than a specific propensity to contracting the disease.

The routine assessment of frailty during the COVID-19 pandemic has been frequently advocated, to facilitate appropriate management and resource allocation [9, 11, 32]. Additionally, in the UK, current NICE guidelines recommend the assessment of frailty as the initial step when assessing suspected COVID-19 patients on admission to hospital [12]. This assessment can then be used to inform decisions for escalation to intensive care environments where ventilatory support can be provided, in the case of patient deterioration. It has also been recommended that people living with multimorbidity or who are likely to be frail should minimise their exposure to the general population to reduce their risk of contracting COVID-19 [33]. To this end, Public Health England implemented a "shielding" strategy on 21st March 2020, with particularly at risk patient groups being contacted based on underlying health conditions, and instructed to selfisolate until further notice [34]. We have not demonstrated any differences in frailty between those testing positive compared with those testing negative for COVID-19 (i.e. when comparing two groups presenting with disease, COVID-19 or otherwise, serious enough to warrant hospital admission). However, our findings do not inform the predictive value of frailty for subsequent outcomes of COVID-19. They do, however, demonstrate that such individuals are generally at high risk of hospitalisation and requiring testing for COVID19 , and therefore risk minimization for older frail or multimorbid individuals remains highly appropriate [35].

Finally, it is important not to view older age as synonymous with frailty when used as a potential risk factor for COVID-19. Whilst the majority of people living with frailty are older persons [23], a notable proportion of frail individuals are middle-aged [16]. The age range at baseline within our sample was 40-69 years, but it is important to note that this was during 2006-2010, and the age range at COVID-19 diagnosis was substantially older (50-84 years). Furthermore, although not statistically significant, the pattern of associations stratified by $<60$ or $\geq 60$ years at baseline was consistent with the notion that frailty markers (here potentially assessed early in their development) might be more relevant in those contracting the COVID-19 at older ages.

\section{Conclusions}

This is the first study to investigate associations between the frailty syndrome, multimorbidity and COVID-19 diagnoses within a large and well characterised prospective observational cohort. We have shown that no differences were evident for frailty status or number of morbidities when comparing those who tested positive for COVID-19 and those who tested negative, suggesting that the associations compared to the background population represent propensity to disease requiring hospital admission, rather than COVID-19 positivity per se. Studies are now urgently needed to examine the prognostic value of frailty and multimorbidity for adverse clinical sequelae following SARS-CoV-2 infection.

Acknowledgements SJW and SD are joint first author. $\mathrm{CC}$ and $\mathrm{NCH}$ are joint senior author.

Author contributions SJW and SD performed the analysis and created the original manuscript, with senior supervision from $\mathrm{NCH}$. CMP gave expert statistical advice. EMC, KW, EMD, HP and CC contributed epidemiological and clinical musculoskeletal/gerontological expertise. All authors reviewed and approved the final manuscript, providing comments and amendments.

Funding This work was supported by the UK Medical Research Council, Wellcome Trust, National Institute for Health Research, Versus Arthritis, Royal Osteoporosis Society Osteoporosis and Bone Research Academy, International Osteoporosis Foundation, NIHR Southampton Biomedical Research Centre, University of Southampton, University Hospital Southampton NHS Foundation Trust and NIHR Oxford Biomedical Research Centre. EMC is supported by the Wellcome Trust (201268/Z/16/Z).(information that explains whether and by whom the research was supported).

\section{Compliance with ethical standards}

Conflicts of interest The authors report no conflicting or competing interests in relation to this work.

Ethics approval This study had ethics approval as part of overall UK Biobank ethics approval (NHS National Research Ethics Service 16/ NW/0274). We undertook the study under UK Biobank Access Application 3593. 
Consent to participate All UK Biobank participants gave written informed consent for data collection, analysis, and linkage.

Consent for publication All UK Biobank participants gave written informed consent for data collection, analysis, and linkage.

Availability of data and material Approval for access to data used in this study is via UK Biobank (approved Access Application 3593).

Code availability All analyses were performed with Stata v 15.1 (StataCorp, College Station, Texas, USA). No custom code was used.

Open Access This article is licensed under a Creative Commons Attribution 4.0 International License, which permits use, sharing, adaptation, distribution and reproduction in any medium or format, as long as you give appropriate credit to the original author(s) and the source, provide a link to the Creative Commons licence, and indicate if changes were made. The images or other third party material in this article are included in the article's Creative Commons licence, unless indicated otherwise in a credit line to the material. If material is not included in the article's Creative Commons licence and your intended use is not permitted by statutory regulation or exceeds the permitted use, you will need to obtain permission directly from the copyright holder. To view a copy of this licence, visit http://creativecommons.org/licenses/by/4.0/.

\section{References}

1. Du Toit A (2020) Outbreak of a novel coronavirus. Nat Rev Microbiol 18:123-123. https://doi.org/10.1038/s41579-020-0332-0

2. World Health Organisation (2020) WHO Director-General's opening remarks at the media briefing on COVID-19 - 11 March 2020. https://www.who.int/dg/speeches/detail/who-director-general-sopening-remarks-at-the-media-briefing-on-covid-19---11-march -2020 . Accessed 25/05/20

3. World Health Organisation (2020) Coronavirus disease 2019 (COVID-19): situation report, 125. https://www.who.int/docs/ default-source/coronaviruse/situation-reports/20200524-covid -19-sitrep-125.pdf. Accessed 25/05/20

4. Boddington N, Charlett A, Elgohari S et al. (2020) COVID-19 in Great Britain: epidemiological and clinical characteristics of the first few hundred (FF100) cases: a descriptive case series and case control analysis. 10.1101/2020.05.18.20086157

5. Surveillances V (2020) The epidemiological characteristics of an outbreak of 2019 novel coronavirus diseases (COVID19)—China, 2020. China CDC Weekly 2:113-122. https://doi. org/10.3760/cma.j.issn.0254-6450.2020.02.003

6. CDC COVID-19 Response Team, Chow N, Fleming-Dutra K et al. (2020) Preliminary estimates of the prevalence of selected underlying health conditions among patients with coronavirus disease 2019-United States, February 12-March 28, 2020. Morbidity and Mortality Weekly Report 69 :382. 10.15585/mmwr. mm6913e2

7. Nanda A, Vura NVRK, Gravenstein S (2020) COVID-19 in older adults. Aging Clin Exp Res 32:1199-1202. https://doi. org/10.1007/s40520-020-01581-5

8. Onder G, Rezza G, Brusaferro S (2020) Case-fatality rate and characteristics of patients dying in relation to COVID-19 in Italy. JAMA 323:1775-1776. https://doi.org/10.1001/jama.2020.4683

9. Abbatecola A, Antonelli-Incalzi R (2020) COVID-19 spiraling of frailty in older Italian patients. J Nutrition Health Aging 24:453455. https://doi.org/10.1007/s12603-020-1357-9
10. Polidori MC, Maggi S, Mattace-Raso F et al (2020) The unavoidable costs of frailty: a geriatric perspective in the time of COVID19. Geriatric Care. https://doi.org/10.4081/gc.2020.8989

11. Sinclair A, Abdelhafiz A (2020) Age, frailty and diabetes-triple jeopardy for vulnerability to COVID-19 infection. E Clin Med. https://doi.org/10.1016/j.eclinm.2020.100343

12. National Institute for Health and Care Excellence (2020) COVID19 rapid guideline: critical care in adults: NICE guideline [NG159]. https://www.nice.org.uk/guidance/ng159. Accessed $25 / 05 / 20$

13. Roller-Wirnsberger R, Lindner S, Liew A et al (2020) European Collaborative and Interprofessional Capability Framework for Prevention and Management of Frailty-a consensus process supported by the Joint Action for Frailty Prevention (ADVANTAGE) and the European Geriatric Medicine Society (EuGMS). Aging Clin Exp Res 32:561-570. https://doi.org/10.1007/s40520-019-01455-5

14. Tay HS, Harwood R (2020) Atypical presentation of COVID-19 in a frail older person. Age Ageing. https://doi.org/10.1093/agein g/afaa068

15. Fried LP, Tangen CM, Walston J et al (2001) Frailty in older adults: evidence for a phenotype. J Gerontol Series A Biolog Sci Med Sci 56:M146-M157. https://doi.org/10.1093/geron a/56.3.m146

16. Hanlon P, Nicholl BI, Jani BD et al (2018) Frailty and pre-frailty in middle-aged and older adults and its association with multimorbidity and mortality: a prospective analysis of $493737 \mathrm{UK}$ Biobank participants. Lancet Public Health 3:e323-e332. https:// doi.org/10.1016/S2468-2667(18)30091-4

17. Ensrud KE, Ewing SK, Cawthon PM et al (2009) A comparison of frailty indexes for the prediction of falls, disability, fractures, and mortality in older men. J Am Geriatr Soc 57:492-498. https ://doi.org/10.1111/j.1532-5415.2009.02137.x

18. Kojima G (2015) Frailty as a predictor of future falls among community-dwelling older people: a systematic review and meta-analysis. J Am Med Direc Assoc 16:1027-1033. https:// doi.org/10.1016/j.jamda.2015.06.018

19. Barnett K, Mercer SW, Norbury M et al (2012) Epidemiology of multimorbidity and implications for health care, research, and medical education: a cross-sectional study. Lancet 380:37-43. https://doi.org/10.1016/S0140-6736(12)60240-2

20. Nicholl BI, Mackay D, Cullen B et al (2014) Chronic multisite pain in major depression and bipolar disorder: cross-sectional study of 149,611 participants in UK Biobank. BMC Psychiatry 14:350. https://doi.org/10.1186/s12888-014-0350-4

21. Armstrong J, Rudkin JK, Allen N et al (2020) Dynamic linkage of COVID-19 test results between Public Health England's Second Generation Surveillance System and UK Biobank. Microb Genom. https://doi.org/10.1099/mgen.0.000397

22. Office for National Statistics (2020) Coronavirus (COVID-19) Infection Survey pilot: England, 21 May 2020. https://www.ons. gov.uk/peoplepopulationandcommunity/healthandsocialcare/ conditionsanddiseases/bulletins/coronaviruscovid19infectionsur veypilot/28may2020. Accessed 25/05/20

23. Collard RM, Boter H, Schoevers RA et al (2012) Prevalence of frailty in community-dwelling older persons: a systematic review. J Am Geriatr Soc 60:1487-1492. https://doi.org/10.111 1/j.1532-5415.2012.04054.x

24. Fang Y, Zhang H, Xie J et al (2020) Sensitivity of chest CT for COVID-19: comparison to RT-PCR. Radiology. https://doi. org/10.1148/radiol.2020200432

25. Long C, Xu H, Shen Q et al (2020) Diagnosis of the Coronavirus disease (COVID-19): rRT-PCR or CT? Eur J Radiol. https://doi. org/10.1016/j.ejrad.2020.108961

26. Woolford S, Sohan O, Dennison E et al (2020) Approaches to the diagnosis and prevention of frailty. Aging Clin Exp Res. https:// doi.org/10.1007/s40520-020-01559-3 
27. Clegg A, Young J, Iliffe S et al (2013) Frailty in elderly people. Lancet 381:752-762. https://doi.org/10.1016/S0140 $-6736(12) 62167-9$

28. Aiden H (2018) Multimorbidity: Understanding the Challenge. Richmond Group of Charities. https://www.richmondgroupof charities.org.uk/sites/default/files/multimorbidity_-_understand ing_the_challenge.pdf. Accessed 25/05/20

29. Vetrano DL, Palmer K, Marengoni A et al (2019) Frailty and multimorbidity: a systematic review and meta-analysis. J Gerontol 74:659-666. https://doi.org/10.1093/gerona/gly110

30. National Institute for Health and Clinical Excellence (2016) Multimorbidity: clinical assessment and management: NICE guideline [NG56]. https://www.nice.org.uk/guidance/ng56. Accessed $26 / 05 / 20$

31. Nunes BP, Flores TR, Mielke GI et al (2016) Multimorbidity and mortality in older adults: a systematic review and meta-analysis. Arch Gerontol Geriatr 67:130-138. https://doi.org/10.1016/j.archg er.2016.07.008

32. Boreskie KF, Boreskie PE, Melady D (2020) Age is just a number-and so is frailty: Strategies to inform resource allocation during the COVID-19 pandemic. Canadian J Emerg Med. https://doi. org/10.1017/cem.2020.358
33. Landi F, Barillaro C, Bellieni A et al (2020) The new challenge of geriatrics: saving frail older people from the Sars-COV-2 pandemic infection. J Nutrition Health Aging 24:466-470. https://doi. org/10.1007/s12603-020-1356-X

34. Public Health England (2020) Guidance on shielding and protecting people who are clinically extremely vulnerable from COVID-19. https://www.gov.uk/government/publications/guida nce-on-shielding-and-protecting-extremely-vulnerable-personsfrom-covid-19/guidance-on-shielding-and-protecting-extremelyvulnerable-persons-from-covid-19. Accessed 26/05/20

35. Palmer K, Monaco A, Kivipelto M et al (2020) The potential long-term impact of the COVID-19 outbreak on patients with noncommunicable diseases in Europe: consequences for healthy ageing. Aging Clin Exp Res 32:1189-1194. https://doi.org/10.1007/ s40520-020-01601-4

Publisher's Note Springer Nature remains neutral with regard to jurisdictional claims in published maps and institutional affiliations. 